to fully transform discoveries into products for patients.

Finally, we would like to point out that the box listing selected schools with bioentrepreneurship programs did not mention the Masters in Biotechnology and Business program that is organized at UCD between the M. Smurfit Graduate School of Business and the School of Biomolecular and Biomedical Science. Gauging the interest from international students, we consider this program worth bringing to the attention of your readers.

\section{COMPETING FINANCIAL INTERESTS \\ The authors declare no competing financial interests.}

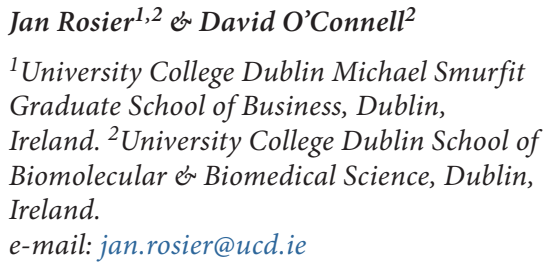

\section{Lynn Johnson Langer replies:}

I agree with many of the comments of Jan Rosier and David O'Connell. Students and entrepreneurs need to understand underlying principles and if and when it is necessary to create new approaches to solve problems that arise in startups. All of our courses in the Johns Hopkins University (JHU; Rockville, MD, USA) Master of Biotechnology Enterprise and Entrepreneurship are grounded in both academic theory and practical applications. As Rosier and O'Connell note, learners will have difficulties thinking outside the box if they do not first understand what is inside the box. Although I agree that understanding the science is critical, so is understanding established theories and practices of business. In the JHU course, we have seen examples where scientists unnecessarily try to create a new business process where an existing business practice will work; conversely, we've seen business people try to inappropriately push along a scientific idea that is not ready to leave the laboratory.

Each side needs to understand the limitations of the other. But, this is a leadership and management shortcoming, rather than a learning issue. Successful leaders need to know when to relinquish decision making to those with specialized knowledge, and our courses help ensure leaders recognize they can't do it all. Also, using the Rosier and O'Connell's regulatory example, many bio-derived products are so new and unique that the standard or current policies and guidelines at a regulatory agency may not apply. A startup's regulatory specialists, scientists and business people must work closely with regulatory agencies to create new ways to regulate never-before-seen products, such as biosimilars. In this case, thinking outside the box is critical.

As to the question of where such programs should be housed, my personal inclination is with some form of science-based programs, or at the least, a partnership between the science department and the business department. This is because the complexity and nature of biotech products require at the very least a fundamental understanding of the science and the environment in which scientists work. Scientists of all types tend to speak with a different vocabulary than business people. They interact with peers differently and prefer to be managed and lead in ways that are often unlike what business schools may present. The key problem is few professionals and academicians are trained in both science and business.
I also concur that program graduates must be able to communicate effectively across a broad spectrum of audiences, from the highly scientific to the lay person. In fact, we offer specific courses, such as 'Bioscience Communication' and 'Managing and Leading Biotechnology Professionals', where students learn to work effectively with peers, supervisors and employees and write scientific abstracts, prepare scientific papers, as well as write for a general audience-these skills are critical. Our students must also have a background in the science of biotech, including biochemistry and cell biology, before entering the program.

My original article discussed the virtual, recently created Society of International Bioentrepreneurship Education and Research (SIBER) in helping corral core competencies and leaders in bioentrepreneurship education. This is a growing field, and the effort at the University of Dublin is noteworthy. Since the article was published, I've heard from several other schools that had not been included. I invite you and others to attend the next meeting of SIBER this June in Copenhagen to further engage in the conversation.

\title{
Increasing patient participation in drug development
}

To the Editor:

An article in your January issue ${ }^{1}$ highlights the struggles of the drug industry to engage with patients on social media. Today, patients take a more active role in their own care $^{2}$; advise the US Food and Drug Administration on what really matters in relation to their disease, diagnosis and treatment ${ }^{3}$; and influence research priorities at the Patient-Centered Outcomes Research Institute in Washington, $\mathrm{DC}^{4}$. However, a similar level of engagement appears to be lacking in pharmaceutical develop-

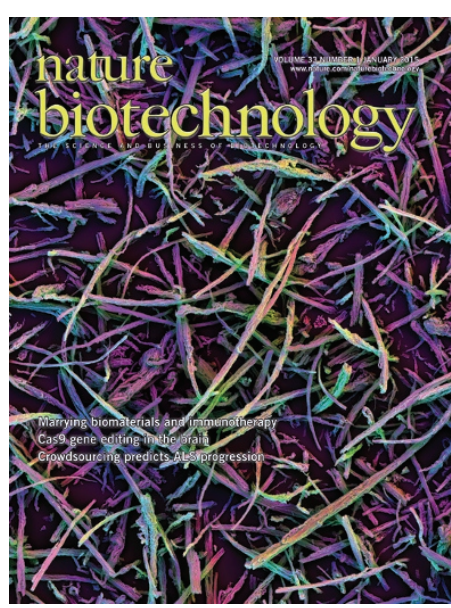

but as true research partners. As focus on patients becomes the norm, listening to them will help companies align scientific, regulatory and reimbursement decision making with the value that patients perceive in new medicines.

Outside industry, Outcome Measures in Rheumatology ${ }^{6}$ and I-SPY 2 (ref. 7) found benefits from patient inclusion, such as developing meaningful outcome measures, highlighting blind spots and overcoming recruitment challenges. The R\&D enterprise would benefit from ment. We propose involving patients in the design and execution of research programs not as merely "empty rituals of participation"5 rapid, scientifically robust and systematically gathered evidence direct from patients living with disease to identify areas of unmet need, 